\title{
Racimo. De los crímenes locales a los crímenes de la globalización
}

\section{Racimo. From the Local Crime to the Crimes of Globalization}

\section{Resumen}

La novela Racimo (2014) de Diego Zúñiga es un ingenioso ensamble de violencias locales y globales que trazan un sutil vaso comunicante entre acontecimientos alejados en el tiempo y el espacio. La novela evoca el pasado traumático chileno desde una mirada peculiar que intenta vincular el Golpe de Estado de 1973 con los atentados terroristas en Nueva York en el 2001. Esto supone un ejercicio interesante en donde la memoria local es sometida a examen desde problemáticas globales contemporáneas. Dicho con otras palabras, la novela sugiere la necesidad de pensar en lo sucesivo el once de septiembre chileno en su vinculación con el once de septiembre norteamericano.

Palabras claves

Diego Zúñiga, Alto Hospicio, 11 de septiembre, memoria, globalización.

\begin{abstract}
The novel Racimo (2014) by Diego Zúñiga is an ingenious assemble of local and global violence that traces a subtle relation between tragic events in different geographies and temporalities. Racimo effectively evokes the traumatic past from a unique perspective that attempts to link the 1973 Copu d'état with the terrorist attacks in New York in 2001. Local memory therefore is questioned from a global perspective. In other words, the novel suggests the need to exanimate the Chilean September 11 through its connection with the 9/11.
\end{abstract}

Keywords

Diego Zúñiga, Alto Hospicio, 9/11, collective memory, globalization. 
La historia reciente de Chile está marcada por tres grandes hitos: la efímera y fracasada empresa socialista en la década del setenta, el largo gobierno militar que se extendió hasta finales de los ochenta, y la reforma económica liberal puesta en marcha durante la dictadura pero ampliada y perfeccionada en democracia a partir de la década del noventa. Considerando la magnitud de estos procesos y el tiempo relativamente corto en que ocurrieron, es fácil comprender que la memoria colectiva constituya un foco de tensión permanente entre los chilenos. En ese sentido la ficción ha jugado un rol fundamental en la construcción subjetiva del pasado pues a través de las múltiples experiencias personales recuperadas desde las narraciones la memoria social se amplía democratizando la historia. Dicho con otras palabras, desde el espacio "seguro" de la ficción es posible recuperar las distintas visiones y versiones del traumático pasado posibilitando así la reflexión que en la esfera política sistemáticamente se pospone o se niega

A más de cuarenta de años del Golpe de Estado de 1973, la literatura chilena mantiene una fuerte tendencia hacia la (re)producción de relatos sobre la memoria. La anterior afirmación no supone ninguna novedad, existe una amplia bibliografía crítica sobre los diversos modos en los que la literatura se ha convertido en el vehículo para la discusión y el debate sobre el pasado traumático reciente. Por dar sólo unos ejemplos, en Memorias del nuevo siglo: jóvenes, trabajadores y artistas en la novela chilena reciente (2009), Rubí Carreño analiza un conjunto significativo de narraciones chilenas recientes desde tres ejes temáticos: trabajadores, jóvenes y artistas, colectivos particularmente castigados durante la dictadura. Por su parte, Mario Lillo en Silencio, trauma y esperanza (2013) clasifica un corpus considerable de novelas chilenas contemporáneas desde los modos bajo los cuales se asume el asedio a la memoria: la crítica visceral que exige además algún tipo de reparación para las víctimas de la dictadura, las novelas que abordan el pasado de manera tangencial y desde un enfoque que busca ser neutral, y los textos que aluden a la memoria sólo de manera elíptica. Como bien señala Lillo, lejos de erigir una verdad histórica unívoca, hasta ahora la narrativa chilena ha 
construido un mosaico múltiple, disímil y contradictorio de experiencias personales que en un última instancia revelan la complejidad de las disputas por la memoria:

el relato de los acontecimientos posteriores a 1973 se ha verificado no en una gran novela total sino a través de múltiples novelas que —en el espíritu de la posmodernidad - dan cuenta de temas, sujetos, espacios, tiempos o destinos de modo parcial, fragmentario, atomizado, desperfilado. (Lillo 43)

El universo narrativo de y sobre la memoria es amplio y variado y tiende inevitablemente al fragmento y la ruptura, a la dispersión permanente de enfoques y posturas. Es el caso de Digo Zúñiga, nacido en lo meses finales de la dictadura pero cuya obra igualmente remite a las disputas en torno a la memoria. En las próximas páginas quisiera analizar la novela de Zúñiga, Racimo (2014) como un ingenioso ensamble de violencias locales y globales que trazan un sutil vaso comunicante entre acontecimientos alejados en el tiempo y el espacio. En la novela de Zúñiga, el pasado traumático chileno es re-visitado desde horrores contemporáneos como el atentado terrorista en la ciudad de Nueva York en los albores del presente siglo. Así, la novela vincula los crímenes locales con los crímenes de la globalización.

Racimo retoma un caso policial real conocido como "los crímenes de Alto Hospicio". De acuerdo con las autoridades chilenas, entre el 12 de septiembre de 1998 y el 23 de agosto del 2001, al menos catorce mujeres (once de ellas menores de edad) fueron secuestradas y asesinadas por un taxista llamado Julio Pérez Silva, conocido como "El psicópata de Alto Hospicio". En la novela de Diego Zúñiga, un fotógrafo de apellidos Torres Leiva forma parte de un equipo de investigación que tratando de resolver los femicidios develarán una compleja red de podredumbre social, política y económica en el triángulo conformado por las poblaciones de Alto Hospicio e Iquique en Chile, y Tacna en Perú. Ahora, para referir los crímenes reales, Zúñiga se permite algunas licencias poéticas cargadas de significación. En 
efecto, dentro de la novela el fotógrafo Torres Leiva se encuentra en la carretera "a una niña haciendo dedo" (Zúñiga 38) con "un corte en la cabeza y el jumper del colegio lleno de tierra" (Zúñiga 38). De inmediato lleva a la niña al hospital y mientras espera noticias sobre su estado en la sala de espera, observa en el televisor imágenes igualmente escabrosas:

El hombre camina directo a la cámara, sin soltar en ningún momento el maletín $[\ldots]$ con una nube de humo a su espalda, avanzado entre escombros, mirando al suelo, sin soltar en ningún momento su maletín. Los periodistas no son capaces de articular un relato, ni siquiera reparan en el hombre; hablan de otras cosas, tratan de dar cifras, de cuantificar el horror, pero no lo consiguen [...].

Ya no está el hombre. Solo queda el humo y las imágenes de los aviones y las torres desmoronándose. (Zúñiga 39-40)

El hombre sujetando el maletín entre el humo y el polvo es una de las tantas imágenes icónicas que dejó el 11 de septiembre del 2001 en la ciudad de Nueva York (de hecho, el exitoso novelista Don DeLillo ficcionalizó la biografía del hombre del maletín en la novela Falling Man publicada en el 2007). El hallazgo de la niña en la carretera y los atentados terroristas en los Estados Unidos quedan ligados a través de una simultaneidad temporal. Este hecho, sin embargo, constituye una alteración deliberada de la cronología real de los crímenes. El psicópata de Alto Hospicio atacó a una joven el día cuatro de octubre del 2001 e intentó asesinarla golpeándola en la cabeza; afortunadamente la joven sobrevivió y logró escapar, siendo incluso capaz de reconocer a su agresor. Unas horas después el asesino fue detenido y puesto a disposición de las autoridades, poniendo punto final a una larga cadena de feminicidios. Estos eventos ocurrieron efectivamente el día cuatro de octubre del 2001, pero Zúñiga decide ubicarlos el día once de septiembre. Además, en la novela el dramático escape de la víctima herida en la cabeza no conduce a la captura del asesino. Es evidente entonces que 
Zúñiga modifica los eventos verídicos para insertarlos en una serie temporal otra que sugiera o evoque una sutil vinculación entre los asesinatos en Alto Hospicio, los ataques terroristas a la nación norteamericana y el Golpe de Estado de 1973 en Chile. Como el hombre del maletín captado por la cámara moviéndose entre la humareda, la novela de Zúñiga con más intuición que certezas intenta discernir entre la bruma los vasos comunicantes entre los distintos sucesos, al parecer interconectados entre sí más allá de una coincidencia en las fechas. Ahondemos en esta dirección.

Dentro de la trama novelística, antes del horrendo hallazgo de la joven herida en la carretera, el aniversario del Golpe de Estado es una presencia incomoda, permanente, a la que no obstante se pretende ignorar o al menos minimizar. "Es 11 de septiembre, sin embargo no cubrirán ninguna pauta en especial. Se cumplen 28 años, pero el editor general dijo que harían una nota breve, no más" (Zíñiga 26-27), señala el texto. Apenas unas líneas después, el narrador señala

La única voz que se escucha es la del locutor, que está informando sobre una reunión en La Moneda entre el presidente Lagos con sus ministros, quienes luego participarán en las distintas actividades para conmemorar el 11 de septiembre. Una fecha complicada, como ustedes saben, pero hasta ahora no se ha registrado ningún incidente, dice el locutor y luego cambia de tema. (Zúñiga 28)

El gesto es ambiguo: el recuerdo del Golpe de Estado está ahí, en la mente del editor del diario, de Torres Leiva, del locutor de la radio, del presidente de la República. Sin embargo, el editor del diario pretende recordar la importancia de la fecha sin ahondar realmente en las implicaciones de los eventos rememorados, el presidente pretende cumplir con las fórmulas con frialdad protocolar y el locutor del radio simplemente cambia de tema. Horas después, el aniversario del Golpe pasará definitivamente a segundo plano ante los eventos locales y globales: el 
descubrimiento de la última víctima del depredador y los atentados terroristas en la ciudad norteamericana. Esto no quiere decir, desde luego, que el pasado reciente pierda relevancia frente a los horrores contemporáneos ni mucho menos que la sociedad quede súbitamente liberada del trauma colectivo. Por el contrario, la memoria adquiere una nueva complejidad al sugerir una implicación ineludible entre episodios alejados en el tiempo y en el espacio. La novela pareciera sugerir que la violencia ejercida contra las jóvenes de Alto Hospicio se explica desde una falla estructural al interior de la sociedad chilena, desde una violencia digamos "primigenia" que de manera irremediable remite a la dictadura. Y esa misma violencia a su vez se proyecta fuera de Chile a través de la pantalla del televisor, delineando una vinculación entre la violencia local y la global que se intuye pero no se entiende. En lo sucesivo, para Diego Zúñiga será necesario tratar de entender lo ocurrido en Chile dentro de una globalidad indiscernible. Más allá de la fecha en común, detrás el bombardeo al Palacio de la Moneda y de los aviones estrellándose en los rascacielos de Manhattan se intuye cierta relación, lejana pero no por ello menos significativa. Pero, una vez más, ¿cómo se conecta el Golpe de Estado de 1973 con los crímenes finiseculares de Alto Hospicio y los atentados en Nueva York del 2001 ?

El Golpe de Estado de 1973, sino orquestado al menos respaldado por los Estados Unidos, supuso el final del gobierno socialista de Salvador Allende. Supuso también el inicio de una profunda reestructuración económica que décadas después instaló a Chile como un actor importante dentro de las economías de libre mercado. En sólo unos años Chile alcanzó niveles de riqueza y desarrollo inéditos en América Latina; paradójicamente, al mismo tiempo al interior del país se agudizó la desigualdad, la marginación y la precarización del empleo. Un ejemplo claro y contundente de este desarrollo desigual es, precisamente, las opuestas realidades de dos poblaciones vecinas, Iquique y Alto Hospicio. Como bien señala Ainhoa Vásquez: 
Alto Hospicio es, entonces, la frontera que funciona simbólicamente como un límite entre unos y otros, entre el bienestar y la miseria, entre lo positivo y lo negativo propagado a distintos ámbitos. Iquique, una de las ciudades más prósperas de Chile, capital de la región de Tarapacá, conocida como la tierra de campeones, gracias a su alta densidad poblacional y a los derechos comerciales que tiene por ser el puerto libre de impuestos más grande de América del Sur, contrasta con la pobreza de Alto Hospicio, construida mediante tomas de terreno y con precarias casas de madera, sin sistema de alcantarillado, sin agua potable, al lado del árido desierto y sin policías que resguarden la seguridad pública o intervengan para capturar a los delincuentes. (58)

Separadas por apenas una docena de kilómetros, la realidad de ambas ciudades no puede ser más distinta. Iquique, que por una circunstancia afortunada en lengua aimara quiere decir "lugar de sueños" y/o "lugar de descanso", es un próspero puerto comercial y un concurrido balneario turístico. Por el contrario, y haciendo también honor a su nombre, Alto Hospicio es una de las tantas villas de miseria, segregación y hacinamiento que abundan en el subcontinente hispánico. Alto Hospicio es la otra cara del desarrollo económico chileno, el mismo que inició con el término abrupto del gobierno de Salvador Allende. Y si bien es cierto que los crímenes reales fueron al parecer obra de un solitario depredador, la precariedad en la que vivían las víctimas contribuyó enormemente al éxito de su modus operandi. La ausencia de escuelas y de transporte seguro en Alto Hospicio obligaba a las adolescentes a hacer dedo cada mañana en la carretera para asistir a los centros educativos de Iquique, circunstancia que aprovechó el "psicópata de Alto Hospicio" para atraerlas con su taxi ofreciéndoles transporte gratuito. Y lo que es más grave aún: cuando los familiares de las víctimas presentaron las denuncias correspondientes, el Estado se deslindó apelando a los conocidos clichés misóginos y clasistas. Al respecto, nuevamente señala Ainhoa Vásquez: 
Como la localidad de Alto Hospicio se definía a partir de la marginalidad, la pobreza y la delincuencia, no resultó extraño para el Gobierno pensar que estas adolescentes se hubieran ido por cuenta propia a otros lugares a ejercer la prostitución. Para enfrentar la escasez, el cuerpo como moneda de cambio podría generar mayores ganancias. Entonces, incluso sin investigar, los policías y las autoridades determinaron de antemano que estas jóvenes bonitas habían elegido "el camino fácil" y se habían escapado con camioneros bolivianos, para prostituirse por mil quinientos pesos chilenos. (59)

Los femicidios reales en los que se basa la novela fueron obra de un agresor serial, pero de algún modo son también los crímenes de la globalización y del capitalismo. Las jóvenes de Alto Hospicio forman parte del desecho, son los parias a los que el Estado no representa y cuya única participación posible en las cadenas de valor pasa por aceptar con resignación la explotación del cuerpo. Así, aunque las autoridades señalasen la prostitución para quitarse de encima la obligación de investigar el paradero de las jóvenes, el destino era sin duda plausible. De ahí que en la trama novelística de Racimo, Torres Leiva se integre a una expedición por entre los burdeles de la fronteriza ciudad de Tacna en busca de las jóvenes chilenas desaparecidas. La pesquisa supone un verdadero descenso al infierno de la prostitución infantil, perfecta y descaradamente visible e impune en la ciudad peruana.

La excursión por entre los bajos fondos de la frontera chileno-peruana revela acaso la peor faceta del capitalismo tardío, aquella que la filósofa tijuanense Sayak Valencia describe con el adjetivo gore. De acuerdo con Valencia, al término de la guerra fría la autoafirmación del capitalismo como la única vía posible creó un nuevo escenario económico en el cual el único marco para regular y establecer los límites entre lo permitido y lo prohibido pareciera sustentarse en la pregunta por el beneficio económico. Sin embargo, a pesar del "triunfo" del capitalismo, el 
acceso al consumo sigue siendo limitado. El deseo de consumir es ya universal, pero las posibilidades reales de acceder a los "beneficios" del consumismo sigue siendo un privilegio reservado. Esta disparidad entre el deseo y la imposibilidad de consumir devino en el crecimiento exponencial de la economía ilegal. De igual modo, la falta de límites digamos éticos pronto favoreció el maridaje entre la economía legal y la ilegal, creando redes de interrelación cada vez más complejas y sofisticadas. Sayak Valencia propone entonces la noción de capitalismo gore para designar las prácticas cada vez más violentas de ciertos actores económicos para obtener los réditos para afirmarse a través del consumo.

Ahora, aunque las prácticas descritas por Sayak Valencia son visibles en múltiples países y contextos, las fronteras son espacios privilegiados para la instauración del capitalismo gore. Después de todo, se trata de espacios ambiguos:

donde se instauran dinámicas dobles que hacen de dichos territorios un espacio donde todo vale; es decir, se las considera el garaje de los dos países. Territorios-puerta, backdoor cities, en los que confluyen de la misma manera simultáneamente, lo indeseable y lo deseable, hibridando estas características y haciendo difícil la aplicación de una axiología tradicional para su conceptualización, creando una especie de ruptura escatológica desde la cual se las concibe como autófagas y siniestras. (134135)

La ininteligibilidad de la frontera, su carácter ambiguo como un "tercer país" que no está sujeto a las leyes de ninguno de los Estados colindantes, resulta idónea para la proliferación de mercados ilegales que incluyen la circulación de mercancías, drogas y personas, la comercialización de la prostitución, la pornografía y el sexo, y un sinfín de prácticas cuestionables. La frontera adquiere entonces un carácter siniestro en las distintas acepciones del término: como un espacio funesto en donde lo reprimido puede manifestarse libremente, y como un espacio accidentado, de catástrofe. Tacna, por ejemplo, es mundialmente famosa 
por ofrecer cirugías estéticas a muy bajo costo, practica aberrante que ha cobrado la vida de miles de mujeres y ha deformado el cuerpo y comprometido la salud de otras tantas. En el caso de la novela, la frontera es el espacio propicio para servirse de la prostitución infantil con absoluta impunidad. Al final, un diputado horrorizado afirma antes los medios:

Aquí hay un grupo de personas a las que el Estado, el Estado chileno y el Estado peruano, tienen en absoluto abandono. Cientos de niños y niñas, cientos de padres y madres que no reciben ayuda para combatir a estas corporaciones que trabajan por la prostitución en el país, en Chile y en el Perú, y quién sabe en cuántos otros países están operando. (Zúñiga 185)

De las chabolas de Alto Hospicio a los burdeles de Tacna, la investigación policial muestra las distintas formas en las que la desigualdad y la explotación golpea a los sujetos más vulnerables. Sí, los asesinatos reales en los que se basa la novela fueron perpetuados por un sólo individuo, pero las condiciones sociales de marginación y pobreza en las que vivían las víctimas son una realidad compartida y padecida lo mismo en Chile que en Perú, en Bolivia o en Paraguay. Diego Zúñiga retoma las coordenadas de la novela negra no para transformar el crimen en un enigma intelectual, sino para mostrar la podredumbre de las sociedades contemporáneas. Al final, el asesino de las jóvenes chilenas es atrapado por las autoridades y condenado a cadena perpetua, pero la población de Alto Hospicio seguirá atrapada en la pobreza y segregación, y las redes de prostitución infantil seguirán operando con plena impunidad en Tacna, Tijuana, Ciudad Juárez o cualquier otra frontera a modo.

Volvamos entonces a la pregunta que quedó pendiente. ¿Cómo se conecta el golpe de Estado en Chile con los asesinatos de Alto Hospicio y los atentados a las torres gemelas en Nueva York? No hay una argumentación directa que permita conectar los eventos y articular una narración lineal en la que causa y efecto afloren con absoluta claridad. La intervención de los Estados Unidos lo mismo en Chile 
que en Oriente Medio para imponer las políticas económicas contemporáneas generó y genera múltiples cataclismos como la agudización de la desigualdad, la proliferación de redes de delincuencia organizada cada vez más complejas, radicalización de la ideología, terrorismo y así un largo etcétera. El Golpe de Estado de Chile en 1973 y los eventos en Nueva York en 2001 están vagamente conectados como el resultado de una intervención violenta del Imperio, la globalización, el libre mercado y otras tantas panaceas siempre celebradas por metrópolis que se reservan el derecho a responder por los monstruos engendrados en la periferia. De hecho, la novela de Zúñiga refiere un hecho trágico previo al asesinato de las jóvenes igualmente cargado de significación: la explosión en 1986 de una bomba racimo producida en secreto por una fábrica clandestina:

Las bombas se hacían durante el día en aquella fábrica y luego, durante la noche, distintos camiones atravesaban esos campamentos que conformaban Alto Hospicio para luego bajar y cruzar Iquique, cuando todos dormían, hasta llegar al puerto y enviarlas a Irak y otros países que estaban en guerra. Era en ese entonces un secreto, o un rumor que a veces se transmitía entre los iquiqueños, que no veían esos camiones, pero los imaginaban bajando por el cerro rumbo al puerto, todos juntos, en fila, cargando esas bombas de racimo cuando la ciudad dormía. Dicen que bajaban a eso de las cuatro de la mañana, quizá a las cinco, cuando la madruagaba se hacía notar en el silencio de las calles, en el frío. Pero nunca nadie los vio realmente, a pesar de que el rumor el jamás desapareció. Prefirieron desviar la mirada, dejar que aquellos camiones recorrieran la ciudad a esa hora fría, pues aquella empresa les daba trabajo a muchos iquiqueños, aquella empresa era vital para la economía del lugar. (Zúñiga 116)

Como los burdeles en Tacna ofreciendo prostitución infantil, la fábrica de bombas en Alto Hospicio opera en la "pública secrecía". Los iquiqueños saben que 
la planta está ahí, incluso se benefician de ella en tanto fuente de empleo, pero la comunidad impone la necesidad de obviar su existencia mediante la celebración de ciertos ritos específicos, como transportar la carga de noche para no ver la amenaza muy real que la fábrica supone. Otro tanto ocurre con las alusiones a los desaparecidos de la dictadura que no faltan en el texto: la comunidad opta por un silencio cómplice que tolera los crímenes a condición de que ocurran en la sombra.

Desde luego, sería tentador buscar en la anécdota de las bombas racimo la clave para develar el sentido oculto del texto. Después de todo, es el título de la obra. Sin embargo, se antoja bastante más acertado buscar en el título una especie de definición de la poética de la misma. Así lo entiende Fermín Rodríguez cuando señala "Racimo hace lo que su título dice: producir con los escombros de la historia agrupamientos de sentido, constelaciones giratorias de relatos anónimos de violencia y represión cargados de un sentido ominoso que la novela se abstiene de explicar" (45). Como los frutos que nacen de un mismo tallo, Diego Zúñiga arroja una serie de fotografías (no en vano el protagonista es fotógrafo) que comparten en lo esencial la geografía, la violencia, la secrecía, y la pobreza moral y material, sin establecer las relaciones últimas entre ellas, como si el hecho de compartir un eje común fuese suficiente. Como bien señalan Daniuska Gónzalez y Alexis Candia, "la realidad globalizada produce, en su faceta más negativa, mercados que ponen en circulación enormes capitales por la venta de drogas, fábricas pestilentes, sujetos a la deriva dentro de sus propios orígenes y pueblos de espaldas a cualquier atisbo de cambio que pueda llegar desde las metrópolis" (González 80). Torres Leiva, cuyo apellido por cierto evoca al trágico incidente neoyorkino, sería en última instancia el responsable de armar un racimo de fotografías que visibilizan la decadencia contemporánea de la que Chile desde luego forma parte.

Recapitulando, Diego Zúñiga forma parte un grupo de narradores chilenos que no vivieron en carne propia la violencia de la dictadura, pero igualmente han padecido las secuelas traumáticas del pasado. La dictadura emerge una y otra vez a lo largo de la novela, como una corriente subterránea que recorre lo narrado y emerge de manera explícita en distintos momentos. Pero lejos de afrontar 
abiertamente el pasado para tratar de conjurarlo, en Zúñiga la memoria se difumina una y otra vez hasta volverse inasible. Como bien señala Lorena Amaro al analizar algunas ficciones de los "hijos", autores entre los que incluye a Diego Zúñiga, "se apropian de algo que no les perteneció plenamente, sino que les perteneció a "ellos", a los padres" (125). De ahí que al tratar de encontrar un sentido, este se aleje una y otra vez dejando apenas una serie de imágenes de violencias locales y globales que de algún modo se intuyen interconectadas entre sí sin que se entienda plenamente el cómo. En ese sentido Patricia Péndola y Patricio Landeta definen Racimo como una novela rizoma:

en tanto las voces que enuncian siguen las multiplicidades descentradas que surgen a medida que van apareciendo los acontecimientos, sin necesidad de organizarlas en un relato con sentido, sin establecer entre ellas jerarquía alguna. En efecto, dichas conexiones rizomáticas atentan contra la idea de un mundo ordenado y organizado por un logos, por una razón que viene a sellar la verdad o necesidad de los hechos que solo en apariencia son frutos del azar; al contrario, dan lugar a distintas líneas de fuga. (39)

Los asesinatos de las jóvenes de Alto Hospicio, la dictadura chilena, los atentados terroristas en los Estados Unidos, la fábrica de bombas, etc., son acontecimientos que se intuyen interrelacionados entre sí pero no hay una explicación última que establezca las conexiones y jerarquice lo narrado. "Porque la memoria no procede siguiendo cadenas causales, describiendo procesos o seleccionando los antecedentes que permitan comprender una época, sino aprehendiendo un tiempo subjetivado en una atmósfera de inmanencia" (Rojas, 236). La memoria, en efecto, más que puntos de referencia ofrece puntos de fuga, por lo que de manera inevitable tiende a la dispersión. No en vano en novelas contemporáneas a Racimo, como Space Invaders (2013) de Nona Fernández o Ruido (2012) de Álvaro Bisama, encontramos aproximaciones al pasado desde 
atmosferas francamente oníricas. A decir de Angélica Franken, los discursos en torno al pasado "se reconfiguran también como basuras, fantasmas y ruidos que conforman la neblina de la memoria" (206). Es la imagen a la que recurre también Zúñiga a través del ejecutivo neoyorkino avanzando entre la polvareda mientras el edificio se desmorona. La neblina, el ruido, el escombro, al parecer no hay otro modo posible de abordar el pasado en un presente en donde la violencia local se funde en una violencia global que igualmente nos agrede y determina.

En cualquier caso, es evidente que en Racimo existe una especie de declaración de principios sobre la necesidad de pensar en lo sucesivo el once de septiembre chileno en su vinculación con el once de septiembre norteamericano. La novela primero reconoce y valida la importancia del 11 de septiembre en el ámbito local y minutos después, a través del cuerpo violentado de una muchachita, se produce un desplazamiento hacia la esfera global a través de los atentados en la ciudad de Nueva York. Más allá de una coincidencia en las fechas, hay en el texto una clara conciencia que intuye un vínculo entre los tres eventos (el Golpe de Estado en Chile, los crímenes de Alto Hospicio y los atentados terroristas en Nueva York) que en última instancia apunta a los monstruos engendrados por el capitalismo y la globalización. El texto otorga imágenes de distintas violencias históricas y contemporáneas tanto en el ámbito local como en el global no precisamente para dar respuestas definitivas sino para dar cuenta del horror y el desencanto. Dentro de las múltiples imágenes icónicas que dejó la tragedia, Zúñiga escoge la de un hombre desorientado avanzando entre la humareda acaso como una metáfora efectiva de los chilenos tratando de encontrar un sentido a la memoria local en el contexto global. En cualquier caso, parece seguro el 11 de septiembre comienza a adquirir una doble significación. 


\section{Bibliografía}

Amaro Castro, Lorena. "Formas de salir de casa, o cómo escapar del Ogro: relatos de filiación en la literatura chilena reciente". Literatura y lingüística, 2014, no 29, p. 96-109.

Areco, Macarena. Cartografia de la novela chilena reciente. Realismos, experimentalismos, hibridaciones y subgéneros. Santiago de Chile: Pontificia Universidad Católica de Chile, 2015.

Bisama, Álvaro. Ruido. México DF: Alfaguara, 2012.

Carreño, Rubí. Memorias del nuevo siglo: jóvenes, trabajadores y artistas en la novela chilena reciente. Santiago: Cuarto propio., 2009.

Fernández, Nona. Space Invaders. Santiago: Alquimia Ediciones, 2013.

Franken Osorio, María Angélica. "Memorias e imaginarios de formación de los hijos en la narrativa chilena reciente". Revista chilena de literatura, 2017, no 96, p. 187-208.

Gónzalez, Daniuska y Alexis Candia Cáseres. "Geografías invisibles de la globalización: Bolaño, Almada y Zúñiga”. Anales de literatura chilena, no.28, 2017, pp. 9-94.

Lillo, Mario. Silencio, trauma y esperanza. Novelas chilenas de la dictadura 1977-2010. Santiago de Chile: Universidad Católica de Chile, 2013.

Mejías Vásquez, Ainhoa. "Feminicidios en la frontera chilena: el caso de Alto Hospicio". Literatura: teoría, historia, crítica, 2016, vol. 18, no 1, pp. 53-74.

Péndola Ramírez, Patricia Angélica y Patricio Alfonso Landaeta Mardones. "Racimo, la novela rizoma de Diego Zúñiga". Literatura y lingüística no, 38, 2018: 35-53.

Rodríguez, Fermín. "Cuerpo y capitalismo: el trabajo de la violencia y el miedo". Estrategias -Psicoanálisis Y Salud Mental-, no, 4, 2016, pp. 43-46. https://revistas.unlp.edu.ar/Estrategias/article/view/2557

Rojas, Sergio. "Profunda superficie: memoria de lo cotidiano en la literatura chilena". Revista chilena de literatura, 2015, no 89, p. 231-256.

Valencia, Sayak. Capitalismo gore. Control económico, violencia y narcopoder. Paidós, 2016.

Zúñiga, Diego. Racimo. Santiago de Chile: Penguin Random House, 2014.

(cc) EY New articles in this journal are licensed under a Creative Commons Attribution 4.0 United States License.

ULS D-Serle This site is published by the University Library System, University of Pittsburgh as part of its D-Scribe Digital Publishing Program and is cosponsored by the University of Pittsburgh Press. 